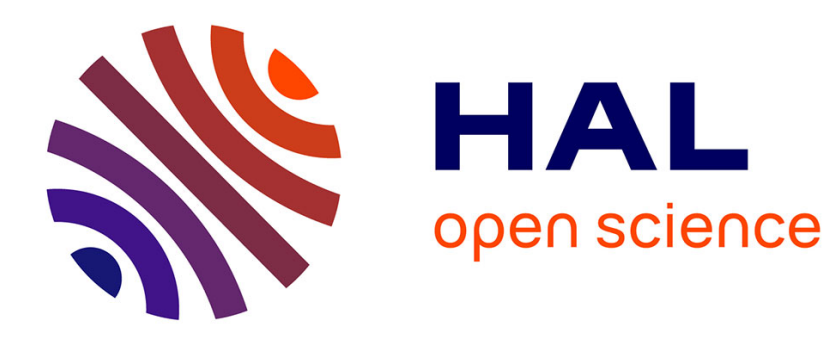

\title{
Cloud droplet activation: solubility revisited
}

L. T. Padró, A. Nenes

\section{To cite this version:}

L. T. Padró, A. Nenes. Cloud droplet activation: solubility revisited. Atmospheric Chemistry and Physics Discussions, 2007, 7 (1), pp.2325-2355. hal-00302591

\section{HAL Id: hal-00302591 \\ https://hal.science/hal-00302591}

Submitted on 16 Feb 2007

HAL is a multi-disciplinary open access archive for the deposit and dissemination of scientific research documents, whether they are published or not. The documents may come from teaching and research institutions in France or abroad, or from public or private research centers.
L'archive ouverte pluridisciplinaire HAL, est destinée au dépôt et à la diffusion de documents scientifiques de niveau recherche, publiés ou non, émanant des établissements d'enseignement et de recherche français ou étrangers, des laboratoires publics ou privés. 
Atmos. Chem. Phys. Discuss., 7, 2325-2355, 2007

www.atmos-chem-phys-discuss.net/7/2325/2007/

(C) Author(s) 2007. This work is licensed

under a Creative Commons License.

\section{Cloud droplet} activation: solubility revisited

L. T. Padró and A. Nenes

\section{Cloud droplet activation: solubility revisited}

\section{T. Padró ${ }^{1}$ and A. Nenes ${ }^{2}$}

${ }^{1}$ School of Chemical and Biomolecular Engineering, Georgia Institute of Technology, 311 Ferst Dr. NW, Atlanta, Georgia 30332, USA

${ }^{2}$ School of Earth and Atmospheric Sciences, Georgia Institute of Technology, 311 Ferst Dr. NW, Atlanta Georgia 30332, USA

Received: 31 January 2007 - Accepted: 7 February 2007 - Published: 16 February 2007

Correspondence to: A. Nenes (nenes@eas.gatech.edu)

Title Page

Abstract Introduction

Conclusions References

Tables Figures

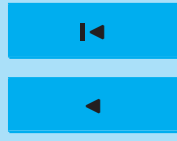
1

Back Close 


\section{Abstract}

Soluble compounds present in atmospheric aerosol facilitate their transformation into cloud droplets by depressing the equilibrium vapor pressure required for activation. Their impact depends on the amount of dissolved substance in the aerosol aqueous 5 phase, which in turn is controlled by its solubility. This study explores the impact of particle curvature on solubility, expressed in terms of a Kelvin enhancement. The augmented solubility, termed "Curvature Enhanced Solubility" (CES), is then introduced into Köhler theory for assessment of its impact on CCN activity for several organic compounds with a wide range of aqueous solubility. The interfacial energy between solute 作 relations based on bulk solubility, and concurrent measurements of contact angle and surface tension. A number of important findings arise from this study: i) CES can substantially increase solubility and impact CCN activity but only if the aerosol is initially wet, ii) CES can stabilize highly supersaturated solutions, and provide a mechanism 15 for retention of an aerosol aqueous phase even at very low relative humidity $(\mathrm{RH})$, and, iii) trace amounts of surfactant impurities can magnify the impact of CES.

\section{Introduction}

The ability of a given aerosol particle to act as a cloud condensation nucleus (CCN) and activate into a cloud droplet is a strong function of its size and composition. Köhler theory (Kohler, 1936) adequately describes CCN composed of inorganic compounds and soluble low molecular weight organic compounds (Cruz and Pandis, 1997; Raymond and Pandis, 2002). CCN containing high molecular weight organic compounds can exhibit complex interactions with water vapor (Corrigan and Novakov, 1999; Raymond and Pandis, 2002; Hartz et al., 2006) which can be further complicated in the 25 presence of inorganic electrolytes (especially bivalent ions, such as $\mathrm{SO}_{4}^{-2}$ ) typically found in ambient aerosol. Unraveling this complexity is needed for aerosol-cloud in-

\section{Cloud droplet} activation: solubility revisited

L. T. Padró and A. Nenes

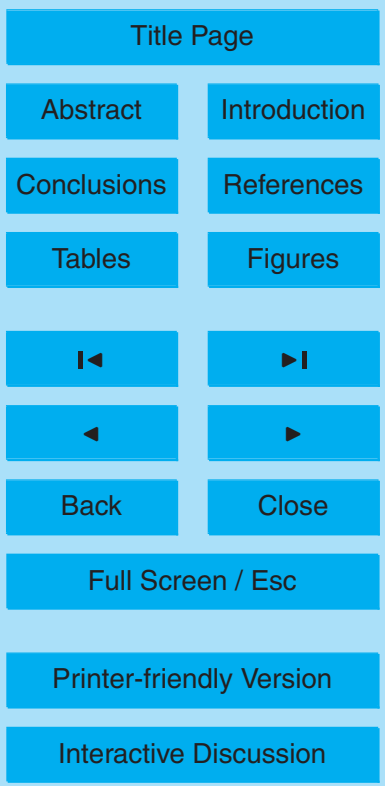


teraction studies, as ambient carbonaceous aerosol can readily act as CCN (Novakov and Penner, 1993).

Theory suggests that solubility in water is an important property controlling CCN activity (Corrigan and Novakov, 1999; Kumar et al., 2003; Broekhuizen et al., 2004). In 5 fact, there is a finite solubility range within which CCN activity can be strongly affected (Nenes et al., 2002); outside this range, the organic is effectively insoluble or always dissolved at the point of activation; in the latter, further increase in solubility would not affect its contribution of solute and CCN activity. Nevertheless, predictions of CCN activity based on limited solubility often disagree with experiments (Hori et al., 2003: Bilde and Svenningsson, 2004; Henning et al., 2005; Padro et al., 2007 ${ }^{1}$ ). Raymond and Pandis (2002) found that most often, the activation of sparingly soluble compounds were consistent with the assumption of complete solubility if the limited solubility compounds tend to spread water (i.e., have a small contact angle with water). This behavior was seen in subsequent studies (Broekhuizen et al., 2004: Henning et al., 2005; Hartz et al., 2006; Padró et al., $2007^{1}$ ) and was attributed to incomplete drying of the particle, where significantly more solute was dissolved in the preexisting water of the particles than predicted by solubility.

The above studies illustrate the importance of knowing the aerosol phase prior to their activation, but attribute the retention of residual water to the existence of a thermodynamically metastable state. Although possible, very high supersaturation levels develop in these concentrated solutions, suggesting that homogeneous nucleation would likely be spontaneous. Enhancing the thermodynamic stability of the aqueous phase may in fact be responsible for the retention of residual water; Marcolli et al. (2004) show that the presence of multiple water-soluble organics can form eutectic mixtures with low deliquescence points. Just as for multicomponent inorganic aerosol (Wexler and Seinfeld, 1991), eutectic points can favor the presence of a thermodynamically

\footnotetext{
${ }^{1}$ Padró, L. T., Morrison, R., Asa-Awuku, A., and Nenes A.: Inferring thermodynamic properties from CCN activation experiments: a) single-component and binary aerosols, in review, 2007.
}

\section{Cloud droplet activation: solubility revisited}

L. T. Padró and A. Nenes

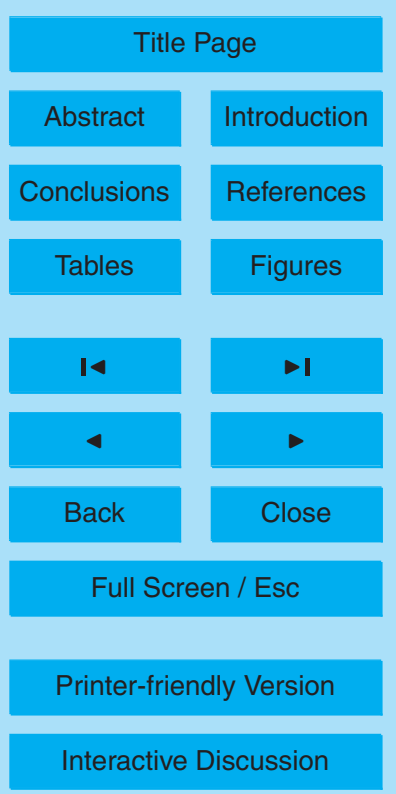

EGU 
stable aqueous phase even at very low relative humidity. Although directly relevant for ambient multicomponent carbonaceous aerosol, eutectics cannot explain the presence of aerosol water seen in the simple aerosol systems examined in the Hori et al. (2003), Bilde and Svenningsson (2004), Henning et al. (2005) and Raymond and Pandis (2002) 5 studies.

This paper proposes an alternate mechanism for stabilizing highly concentrated aqueous solutions, which we term Curvature-Enhanced Solubility (CES). When a fully hydrated aerosol is exposed to a low relative humidity environment (for example during the drying phase of a typical aerosol generation apparatus in the laboratory), it eventu10 ally forms a supersaturated solution that tends to form stable nucleation clusters, upon which subsequent condensation of solute eventually leads to the formation of a dry particle. The curvature of the initial solute cluster however can raise the solute chemical potential in the solid phase; in other words, the solute in the curved particle can have a higher solubility than its "bulk" value. The property that controls the magnitude

of CES is the interfacial energy (otherwise known as "interfacial tension") between the solid nucleus and surrounding liquid solution. Therefore, if the curvature and interfacial energy is high enough (which is certainly possible for nanometer-scale particles), this enhanced solubility may inhibit the subsequent condensation of solute from the aqueous phase, which results in a thermodynamically stable aqueous phase even at very low relative humidity's (Fig. 1).

In order to assess the relevance of curvature enhanced solubility (CES) for CCN activation and water retention at low $\mathrm{RH}$, we studied nine organic compounds that exhibit a wide range of solubility. For each compound, its interfacial tension with water is determined based on measurements of aqueous solution surface tension, wettability

(contact angle with water) and an equation of state (Spelt and Li, 1996). The interfacial tension is introduced into Köhler theory and the equilibrium saturation vapor pressure is calculated with and without CES. For each case, predictions of CCN activity are compared with observations and the results are discussed.
ACPD

7, 2325-2355, 2007

\section{Cloud droplet}

activation: solubility revisited

L. T. Padró and A. Nenes

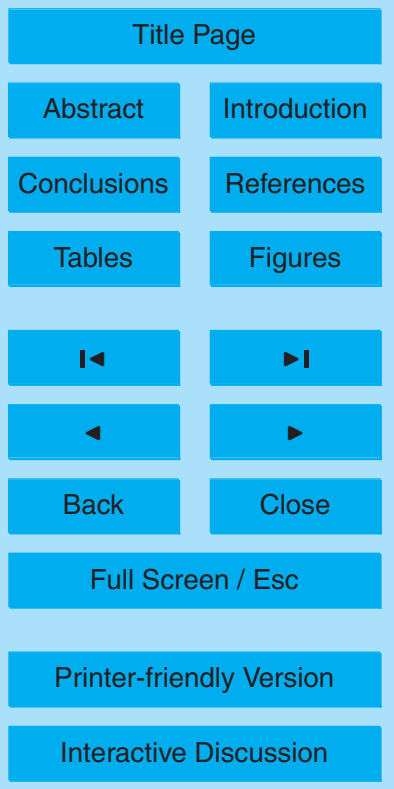




\section{Theory of CES and its impact on CCN activity}

\subsection{Traditional Köhler theory}

The Köhler equation expresses the equilibrium saturation ratio, $S_{e q}$, (defined as the ratio of the droplet water vapor pressure and the saturation water vapor pressure over

5 a flat surface) of the CCN with its environment. For a deliquescent single-component $\mathrm{CCN}, S_{e q}$ is given by,

$S_{e q}=\frac{P_{w}}{P^{o}}=\exp \left(\frac{4 M_{w} \sigma_{w}}{R T D_{p}}-\frac{6 v \phi n_{s} M_{w}}{\pi \rho_{w} D_{p}^{3}}\right)$

where $P_{w}$ is the droplet water vapor pressure, $D_{p}$ is the CCN wet diameter, $P^{o}$ is the saturation vapor pressure for pure water over a flat surface at temperature $T, M_{w}$ is the

$\rho_{w}$ is the density of $\sigma_{w}$ is the $v$ is the van't Hoff factor, $\phi$ is the osmotic coefficient, and $\rho_{w}$ is the density of water, $u$ is the van't Hoff factor, $\phi$ is the osmotic coefficient, and $n_{s}$ is the moles of solute. The Kelvin (or "curvature") effect in Eq. (1) is governed by the $D_{p}^{-1}$ term, while the solute effect is governed by the $D_{p}^{-3}$ term. The maximum of Eq. (1) corresponds to the minimum (or "critical") saturation ratio required for the CCN to become an unstable cloud droplet.

If the $\mathrm{CCN}$ is composed of a soluble fraction, $s$, and a partially soluble fraction, $s s$, Eq. (1) can be expressed as (Shulman et al., 1996),

$S_{e q}=\exp \left(\frac{4 M_{w} \sigma_{w}}{R T \rho_{w} D_{p}}-\frac{6 n_{s} M_{w} v_{s}}{\pi \rho_{w} D_{p}^{3}}-\frac{6 n_{s s} M_{w} v_{s s}}{\pi \rho_{w} D_{p}^{3}}\right)$

where $n_{s}, n_{s s}$ represent the moles of solute dissolved in the droplet from the soluble and slightly soluble species, respectively; $v_{s}, v_{s s}$ are the corresponding "effective" van't Hoff factors. If not all the ss is dissolved and dissolution kinetics (Asa-Awuku and

\section{Cloud droplet} activation: solubility revisited

L. T. Padró and A. Nenes

Title Page

Abstract

Conclusions

Tables References

Figures

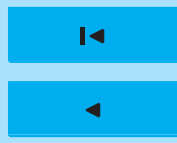

$\rightarrow$

Back

Close

Full Screen / Esc

Printer-friendly Version

Interactive Discussion 
Nenes, 2007) are unimportant, then the equilibrium solubility, $C_{e q}$, can be used to compute $n_{s s}$. Expressing $C_{e q}$ in moles $\mathrm{m}^{-3}$, Eq. (2) becomes,

$S_{e q}=\exp \left(\frac{4 M_{w} \sigma_{w}}{R T \rho_{w} D_{p}}-\frac{6 n_{s} M_{w} v_{s}}{\pi \rho_{w} D_{p}^{3}}-\frac{M_{w}}{\rho_{w}} C_{e q} v_{s s}\right)$

\subsection{The effect of solute core curvature}

5 For a substance that partitions between a solid and aqueous phase, curvature of the solid-aqueous interface and non-zero interfacial energy tends to affect this partitioning (i.e., the solubility); this is expressed by the Kelvin equation as

$$
\frac{C_{e q}}{C_{\text {bulk }}}=\exp \left(\frac{4}{R T} \frac{M_{s}}{\rho_{s}} \frac{\gamma_{s l}}{d_{\text {core }}}\right)
$$

where $C_{e q}$ is the equilibrium solubility of the compound over the curved interface, $C_{\text {bulk }}$ is the solubility of the compound over a flat surface ("bulk solubility"), $M_{s}$ is the molar mass of the solute, $\rho_{s}$ is the solute density, $\gamma_{s /}$ is the solute-aqueous phase interfacial energy and $d_{\text {core }}$ is the diameter of the solute "droplet inclusion". Equation (4) suggests that the solubility enhancement depends strongly on the size of $d_{\text {core }}$ and $\gamma_{s /}$. Most often $\gamma_{s l} \geq 0$ (Spelt and Li, 1996), hence $\frac{C_{e q}}{C_{\text {bulk }}} \geq 1$. Negative interfacial energies, which 15 have been reported for sparingly soluble minerals (Wu and Nancollas, 1999) and some polymers (Holmberg et al., 2003 ), would result in $\frac{C_{e q}}{C_{\text {bulk }}}<1$; however such cases are rare and not considered in this study.

2.3 When is bulk solubility not enough to explain CCN activity?

As the amount of water available at the critical point depends on critical supersatura20 tion, it is important to assess the conditions for which bulk solubility alone is insufficient to characterize the observed CCN activity. This is accomplished by theoretically

\section{Cloud droplet} activation: solubility revisited

L. T. Padró and A. Nenes

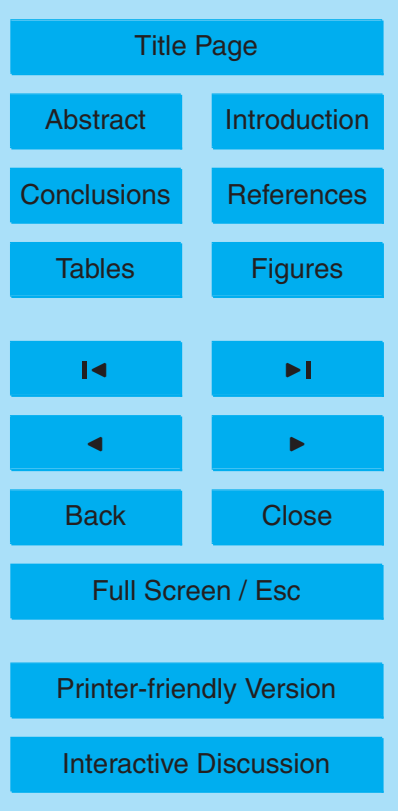

EGU 
estimating the moles of solute required for activating $\mathrm{CCN}$ for a given critical supersaturation; the required moles are then compared to those available from solubility. Compounds and supersaturation conditions are then identified for which CES can potentially be important.

5 Assuming that a $\mathrm{CCN}$ is composed of a single compound, critical supersaturation, $s_{C}$, is related to CCN physical properties by (Seinfeld and Pandis, 1997),

$s_{c}=\frac{2}{3}\left(\frac{4 M_{w} \sigma_{w}}{R T \rho_{w}}\right)^{3 / 2}\left(\frac{18 n_{s} M_{w} v_{s}}{\pi \rho_{w}}\right)^{-1 / 2}$

from which the number of moles, $n_{s}$, required for the CCN to activate at $s_{C}$ is

$n_{s}=\frac{2}{81} \frac{\pi \rho_{w}}{v_{s} M_{w}}\left(\frac{4 M_{w} \sigma_{w}}{R T \rho_{w}}\right)^{3} s_{c}^{-2}$

10 If the bulk solubility of a compound, $C_{\text {bulk }}$, is given in moles solute per $\mathrm{m}^{3}$ solution, then the number of moles available from bulk solubility, $n_{\text {bulk }}$, at the point of activation is $n_{\text {bulk }}=\frac{\pi}{6} D_{c}^{3} C_{\text {bulk }}$, where $D_{c}$ is the $C C N$ critical diameter (here we assume that the point of activation, the $\mathrm{CCN}$ is mostly composed of water, hence the volume of water available for dissolution is $\left.\frac{\pi}{6} D_{c}^{3}\right)$. Since $D_{c}=\frac{2}{3}\left(\frac{4 M_{w} \sigma_{w}}{R T \rho_{w}}\right) \frac{1}{s_{c}}$ (Seinfeld and Pandis, 1997),

$15 n_{\text {bulk }}$ is given by

$n_{\text {bulk }}=\frac{4}{81} \pi\left(\frac{4 M_{w} \sigma_{w}}{R T \rho_{w}}\right)^{3} s_{C}^{-3} C_{\text {bulk }}$

The ratio, $\Phi$, of $n_{s}$ over $n_{\text {bulk }}$ is then calculated from Eqs. (6) and (7),

$\Phi=\frac{n_{s}}{n_{\text {bulk }}}=\frac{1}{2} \frac{\rho_{w}}{v_{s} M_{w}} \frac{s_{c}}{C_{\text {bulk }}}$

$\Phi<1$ indicates that bulk solubility alone is sufficient to explain CCN activity of compounds, while $\Phi>1$ requires an enhancement of solubility that could be a result of CES.

Full Screen / Esc

Cloud droplet activation: solubility revisited

L. T. Padró and A. Nenes

Title Page

Abstract

Introduction

Conclusions

Tables

References

Figures

14

$\triangleleft$

Back

Close

Printer-friendly Version

Interactive Discussion 


\subsection{Introducing CES in Köhler theory}

Introduction of CES into Köhler theory is relatively straightforward. For a given wet diameter, $C_{e q}$ from Eq. (4) is calculated and then introduced into Eq. (3). The application of Eq. (4) however requires knowledge of the solute core diameter, $d_{\text {core }}$, and

$5 \gamma_{s /}$. The latter is determined from contact angle and surface tension measurements (Sect. 3), and $d_{\text {core }}$ is computed from the solute mass balance, as follows. As the mass of solute in the core must equal the mass of solute in the dry particle minus the amount dissolved in water,

$$
d_{\text {core }}^{3} \rho_{s}=d_{\mathrm{dry}}^{3} \rho_{s}-D_{p}^{3} C_{e q}
$$

10 where $d_{\text {dry }}$ is the dry particle diameter (original core diameter). Introducing the modified solubility (Eq. 4) into Eq. (9) yields,

$d_{\text {core }}^{3}+\frac{D_{p}^{3} C_{\text {bulk }}}{\rho_{s}} \exp \left(\frac{4}{R T} \frac{M_{s}}{\rho_{s}} \frac{\gamma_{s I}}{d_{\text {core }}}\right)-d_{\text {dry }}^{3}=0$

which is a nonlinear equation, the solution of which yields the value of $d_{\text {core }}$ for a given $D_{p}$. Figure 2 shows the algorithm used for "mapping out" Köhler curves influenced by CES.

\subsection{When can CES affect CCN activity?}

CES can considerably facilitate CCN activation, as far more solute can be in solution than based on "bulk" solubility alone. However, for this to happen, the "droplet inclusion" needs to be small enough for the exponential increase in solubility (Eq. 4) to create an

instability that spontaneously dissolves most of the solute core. Equation (10) thus has multiple solutions, one for when $d_{\text {core }}$ is relatively large (i.e., the exponential is close to unity), and one for when $d_{\text {core }}$ is relatively small (i.e., the exponential is very large); this is illustrated in Fig. 3 , which presents the value of $f\left(d_{\text {core }}\right)$ (where $f$ denotes the left hand

\section{Cloud droplet} activation: solubility revisited

L. T. Padró and A. Nenes

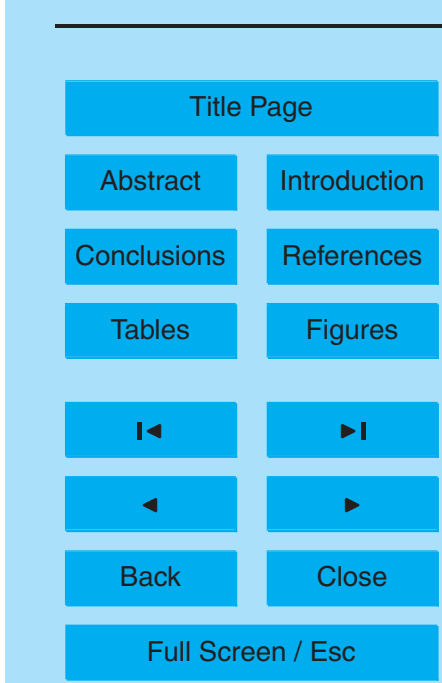

Printer-friendly Version

Interactive Discussion 
side of Eq. 10) for a wet CCN with $D_{p}=0.5 \mu \mathrm{m}, \rho_{s}=1760 \mathrm{~kg} \mathrm{~m}^{-3}, M_{s}=0.132 \mathrm{~kg} \mathrm{~mol}^{-1}$, $C_{\text {bulk }}=1 \mathrm{~g} \mathrm{~kg}^{-1}, d_{\text {dry }}=100 \mathrm{~nm}, \mathrm{~T}=298 \mathrm{~K}$. As expected, $f\left(d_{\text {core }}\right)=0$ yields one solution for $\gamma_{s l}=0$. For non-zero interfacial tension, $f\left(d_{\text {core }}\right)=0$ yields two solutions, one when $d_{\text {core }}$ is large (i.e., CES is small); this solution, $d_{\text {core, max }}$, can be approximated from Eq. (6), 5 assuming that $\exp \left(\frac{4}{R T} \frac{M_{s}}{\rho_{s}} \frac{\gamma_{S I}}{d_{\text {core }}}\right) \approx 1$,

$d_{\text {core, } \max } \approx\left(d_{\text {dry }}^{3}-\frac{D_{p}^{3} C_{\text {bulk }}}{\rho_{s}}\right)^{1 / 3}$

In the region where CES dominates (small $\left.d_{\text {core }}\right), f\left(d_{\text {core }}\right)=0$ yields another solution, $d_{\text {core,min }}$, and can be approximated from Eq. (10), assuming that $d_{\text {core }}<<d_{\text {dry }}$,

$d_{\text {core } \min } \approx \frac{4}{R T} \frac{M_{s} \gamma_{s l}}{\rho_{s}}\left(\ln \frac{\rho_{s} d_{\text {dry }}^{3}}{D_{p}^{3} C_{\text {bulk }}}\right)^{-1}$

10 The sign of $f\left(d_{\text {core }}\right)$ also determines the saturation state of the aqueous phase surrounding the solute core; if an excessive amount of solute is dissolved, $f\left(d_{\text {core }}\right)<0$ and the solution is supersaturated, and vice versa (Fig. 3). With this in mind, one could then understand the dynamics of the $\mathrm{CCN}$ when some water condenses upon it. We consider two initial states: $i$ ) the $\mathrm{CCN}$ is dry, and, $i i$ ) the $\mathrm{CCN}$ is completely wet (i.e., all solute is dissolved).

- If the particle is initially dry, then $d_{\text {core }}=d_{\text {dry }}$. Adding a small amount of water on to the CCN (Fig. 4a, black line) would then result in an unsaturated aqueous phase (i.e., $f\left(d_{\text {core }}\right)>0$, to the right of $\left.d_{\text {core, max }}\right)$. Solute will then dissolve (i.e., $d_{\text {core }}$ shifts leftward) until $d_{\text {core }}=d_{\text {core, } \max }$ (Eq. 11). $d_{\text {core,max }}$ is a stable equilibrium point, as small fluctuations in $d_{\text {core }}$ would result in mass transfer to/from the aqueous phase that would restore $d_{\text {core }}$ to $d_{\text {core, max }}$. Further addition of water to the CCN would always result initially in an unsaturated aqueous phase (i.e., $f\left(d_{\text {core }}\right)>0$, to

Cloud droplet activation: solubility revisited

L. T. Padró and A. Nenes

Title Page

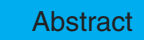

Introduction
References

Conclusions

Tables

Figures

14

4

Back

Close

Full Screen / Esc

Printer-friendly Version

Interactive Discussion 
the right of $d_{\text {core,max }}$ ) after which some solute is dissolved until a new equilibrium is reached (Fig. $4 \mathrm{a}$, blue line). However, every time some water is added to the CCN, $d_{\text {core, max }}$ and $d_{\text {core, min }}$ approach each other until they become equal (Fig. $4 \mathrm{a}$, red line); at this point, further addition of water would result in $f\left(d_{\text {core }}\right)>0$ for all values of $d_{\text {core }}$, hence the solution is always undersaturated (because of CES) and the core spontaneously dissolves (Fig. 4a, green line).

- If the particle is initially wet, then $d_{\text {core }}=0$, as the solution is undersaturated with solute (Fig. 4b, green line). Removing a small amount of water from the CCN (Fig. 4b, blue line) results in a supersaturated aqueous phase which favors the formation of a solid core, by nucleation of a core embryo of size $d^{*}$ and subsequent condensation of solute. If $d^{*}<d_{\text {core, min }}$ (Fig. $4 \mathrm{~b}$, blue line) then CES is substantial, the solution becomes undersaturated with solute (i.e., $f\left(d_{\text {core }}\right)>0$ ), the nucleation

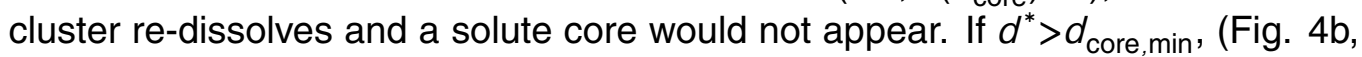
black line) then CES is not substantial, and the aqueous phase is always supersaturated with respect to solute (i.e., $f\left(d_{\text {core }}\right)<0$ ); solute then continuously condenses upon the core embryo, until a equilibrium is reached, i.e., $d_{\text {core }}=d_{\text {core, } \max }$. The above suggests that $d_{\text {core,min }}$ is an unstable equilibrium point, as small fluctuations in $d_{\text {core }}$ would result in either complete dissolution of the core (if $d_{\text {core }}$ fluctuates to a size slightly smaller than $d_{\text {core, min }}$ ) or spontaneous growth to $d_{\text {core, max }}$ (if $d_{\text {core }}$ fluctuates to a size slightly greater than $d_{\text {core,min }}$ ).

From the discussion above, the following implications arise:

- CES may not substantially enhance CCN activity if the aerosol is initially dry. When enough water is added to the aerosol (so that $d_{\text {core }} \sim d_{\text {core, min }}$ ), CES enhances solubility enough to spontaneously dissolve the core. The wet diameter for spontaneous dissolution corresponds to the minimum of the red curve in Fig. 4 a which can be found by solving the system $\frac{\partial f\left(d_{\text {core }}\right)}{\partial d_{\text {core }}}=0 ; f\left(d_{\text {core }}\right)=0$ for $d_{\text {core }}$ and $D_{p}$.

\section{Cloud droplet activation: solubility revisited}

L. T. Padró and A. Nenes

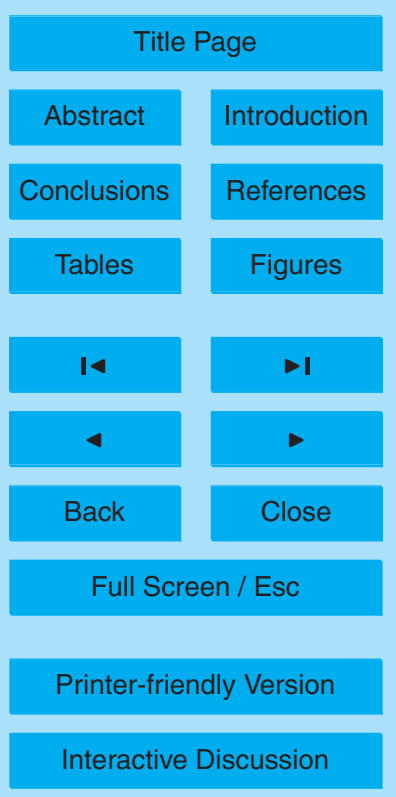

EGU 
- Aerosol that is initially wet can retain its water at very low relative humidity, as long as the nucleation embryo size $d^{*}<d_{\text {core,min }}$. When $d^{*}>d_{\text {core, min }}$, CES is not strong enough to maintain a thermodynamically stable state. Therefore, $d^{*}=d_{\text {core, min }}$ denotes the transition point between a completely wet and (primarily) dry aerosol, when applied to Eq. (12), gives the minimum wet size, $D_{p \text {,min }}$ for a thermodynamically stable wet aerosol:

$D_{p, \min } \approx d_{\text {dry }}\left\{\frac{\rho_{s}}{C_{\text {bulk }}} \exp \left(\frac{4}{R T} \frac{M_{s} \gamma_{s l}}{\rho_{s} d^{*}}\right)\right\}^{1 / 3}$

The magnitude of $d^{*}$ depends strongly on the interfacial tension, the geometry of the nucleation cluster and the level of solute supersaturation (Nielsen, 1964; Wu and Nancollas, 1999) and vary from a few $\mathrm{nm}$ to the particle dry size.

\section{Obtaining interfacial energy: the contact angle method}

$\gamma_{s /}$ is related to the surface tension and contact angle, $\theta$, between organic and aqueous solution, according to the Young-Laplace equation (Spelt and Li, 1996),

$\gamma_{s l}=\gamma_{s V}-\sigma \cos \theta$

15 where $\gamma_{S V}$ is the surface energy of the solid core. It can be shown (Spelt and Li, 1996) that an equation of state exists relating $\sigma, \gamma_{s l}$, and $\gamma_{s v}$,

$\gamma_{s l}=\sigma+\gamma_{s v}-2 \sqrt{\sigma \gamma_{s v}} e^{-\beta\left(\sigma-\gamma_{s v}\right)^{2}}$

where $\beta$ is a "universal constant". From least-squares fit to contact angle and liquid surface tension measurements of many compounds, $\beta=0.000115\left(\mathrm{~m}^{2} \mathrm{~mJ}^{-1}\right)^{2}$ (Spelt and $\mathrm{Li}, 1996$ ). Equations (14) and (15), combined with measurements of $\sigma$ and $\theta$ can be used to determine $\gamma_{s l}$ and is known as the "contact angle method". Two other methods can be used to determine $\gamma_{s l}, i$ ) solubility-size measurements, and, ii) crystallization and dissolution kinetics. The former method is subject to significant uncertainty

\section{Cloud droplet} activation: solubility revisited

L. T. Padró and A. Nenes

Title Page

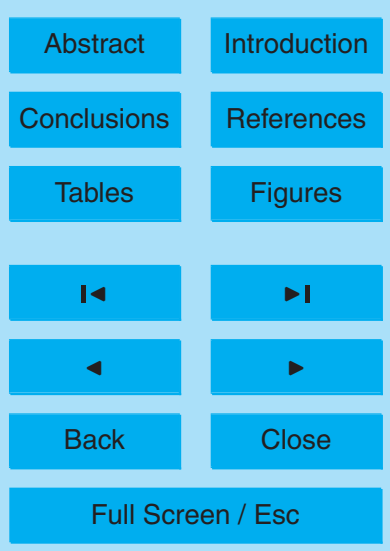

Printer-friendly Version

Interactive Discussion 
while the latter gives values consistent with those calculated through the contact angle method (Wu and Nancollas, 1999). Studies have shown that for inorganic and organic compounds, solubility increases as the interfacial energy decreases (Sohnel, 1982; Wu and Nancollas, 1998; Wu and Nancollas, 1999). Therefore, sparingly soluble

5 compounds with hydrophobic characteristics, because of the expected high $\gamma_{s l}$, may present enhanced solubility from CES if in the form of small particle inclusions in the aqueous solution.

\section{CES for single-component organic CCN}

The importance of CES on solubility and CCN activity is assessed for nine organic 10 compounds: adipic acid, glutamic acid, glutaric acid, norpinic acid, pinic acid, pinonic acid, azelaic acid, phthalic acid and leucine (Table 1). These compounds were selected for their atmospheric relevance, their wide range of solubility in water (Table 1) and for some (adipic acid and glutaric acid) their well-studied CCN characteristics (Cruz and Pandis, 1997; Corrigan and Novakov, 1999; Prenni et al., 2001; Raymond and 15 Pandis, 2002; Hori et al., 2003; Kumar et al., 2003; Bilde and Svenningsson, 2004; Broekhuizen et al., 2004; Hartz et al., 2006).

In Table 2, the values of $\Phi$ for the nine organics and four levels of supersaturation $(0.3,0.6,1.0$, and $1.2 \%)$ are shown. When $\Phi<1$, bulk solubility alone is sufficient to explain the CCN activity of the compounds (Sect. 2.3), while an enhancement in solubility is required when $\Phi>1$. Of the compounds studied, only the CCN activity of glutaric acid and pinic acid is always consistent with their bulk solubility $(\Phi<1)$. For the other seven compounds, conditions exist for which bulk solubility alone is insufficient $(\Phi>1)$ to explain the CCN activity of the compound (Table 2). $\Phi>1$ occurs more often at high supersaturations, as less water is available at the point of activation (because

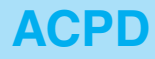

7, 2325-2355, 2007

\section{Cloud droplet} activation: solubility revisited

L. T. Padró and A. Nenes

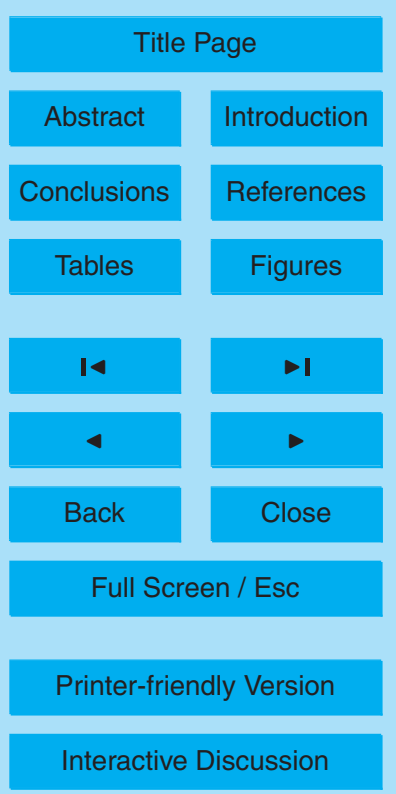




\subsection{Interfacial energy for the compounds studied}

For three of the compounds considered in this study (azelaic acid, phthalic acid, and leucine), we determined interfacial energy using the contact angle method (Sect. 3). Surface tension and contact angle for each compound were measured using a KSV

5 Inc. CAM 200 Optical Contact Angle Meter. With this instrument, the shape of the pendant drops are fit to the Young-Laplace equation (Spelt and $\mathrm{Li}, 1996$ ) from which surface tension is determined. The contact angle is determined from a sessile drop upon a flat substrate of compound. The substrate was applied by evaporation of a solution of the compound upon a glass plate and placing the plate within a diffusional dryer for one day. The concentration of the solution had a significant impact on the surface roughness; it was found that using solutions diluted down to $1 / 4$ their saturation value gave the smoothest surface. Contact angles were measured for sessile drops composed of pure water and of saturated solution, and surface tension was measured for pure water and for saturated solutions of organic.

15 Table 3 shows the surface tension, contact angle and calculated interfacial energy for organic/water and organic/saturated aqueous solution systems. Contact angle measurements were repeated at least ten times, and surface tension measurements were repeated at least fifty. Larger contact angles are consistently obtained when a saturated solution is placed upon the substrate. This phenomenon is likely from the dissolution of the substrate layer by the pure water; if so, the underlying hydrophilic glass will come into contact with the water drop and reduce the contact angle (this is consistent with the observation that contact angle changes slowly with time). Dissolution of substrate is less likely to happen when placing saturated solution drops on the substrate; this is corroborated by the higher contact angle and their stability with time. Surface heterogeneities are likely not affecting the contact angle because $i$ ) we did not observe substantial variability between repetition of the measurement, and, ii) the angle measured on both sides of the drop cross section were not substantially different. Based on the above, we use only the interfacial energy values obtained from surface tension

\section{Cloud droplet activation: solubility revisited}

L. T. Padró and A. Nenes

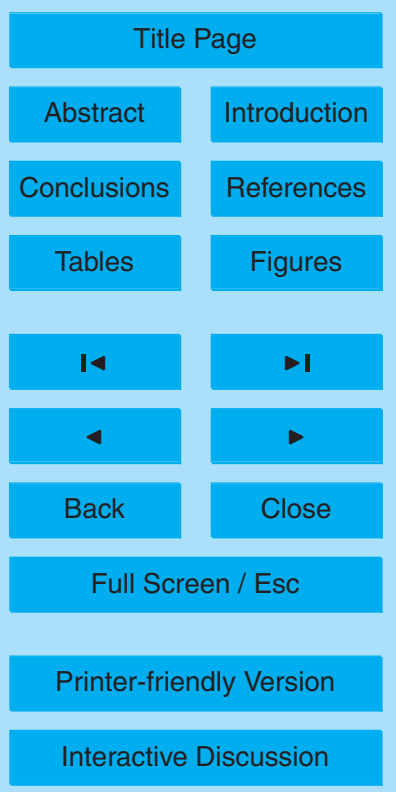

EGU 
and contact angle measurements of saturated solutions (Table 3).

Our measurements are compared with the interfacial energy - solubility correlation of Söhnel (1982) to assess their consistency with existing measurement database. Leucine is fairly close to the correlation, while azelaic and phthalic acid substantially 5 deviate from the correlation (Fig. 5). The discrepancy of the latter two compounds could indicate the presence of small amounts of surfactant impurities which can substantially decrease interfacial energy. For the remaining compounds studied (adipic acid, glutamic acid, glutaric acid, norpinic acid, pinic acid, pinonic acid), interfacial energy is determined using the solubility-interfacial energy correlation by Söhnel (1982). Given 10 the uncertainty of the correlation, we varied $\gamma_{s /}$ between 0 and $60 \mathrm{mN} \mathrm{m}^{-1}$ consistent with the uncertainty in Söhnel's correlation (Fig. 5).

\subsection{Impact of CES on Köhler curves}

Köhler curves are examined for compounds and conditions for which $\Phi>1$ (Table 2). From the discussion of Sect. 2.5, Köhler curves computed without CES are more rep15 resentative of particles that are initially completely dry while curves that include CES correspond to particles that are initially wet and subsequently dried (which represents how aerosol are typically generated in laboratory experiments). Köhler curves were computed for leucine, pinonic acid and pinic acid particles with dry diameter ranging from 10 to $500 \mathrm{~nm}$ (Fig. 6). In all calculations, we take the critical cluster diameter $d^{*}$ 20 to be $5 \mathrm{~nm}$. CES has a strong impact on the shape of the equilibrium curve for all three compounds examined. For leucine (Fig. 6a) and pinic acid (Fig. 6c), the CES is strong enough to always keep the solute dissolved in the aqueous phase, consistent with the "complete solubility" behavior seen previously for these compounds (Raymond and Pandis, 2002). As a result, the CCN critical supersaturation substantially decreases, 25 from $\sim 1.5 \%$ (without CES) to $0.4 \%$ (with CES) for leucine, and $\sim 1.1 \%$ (without CES) to $0.5 \%$ (with CES) for pinic acid. For the sparingly soluble pinonic acid (Fig. 6b), not considering CES yields a Köhler curve which is always dominated by the Kelvin effect, in which the critical supersaturation is the equilibrium supersaturation at the dry diam-

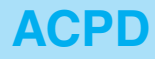

$7,2325-2355,2007$

\section{Cloud droplet activation: solubility revisited}

L. T. Padró and A. Nenes

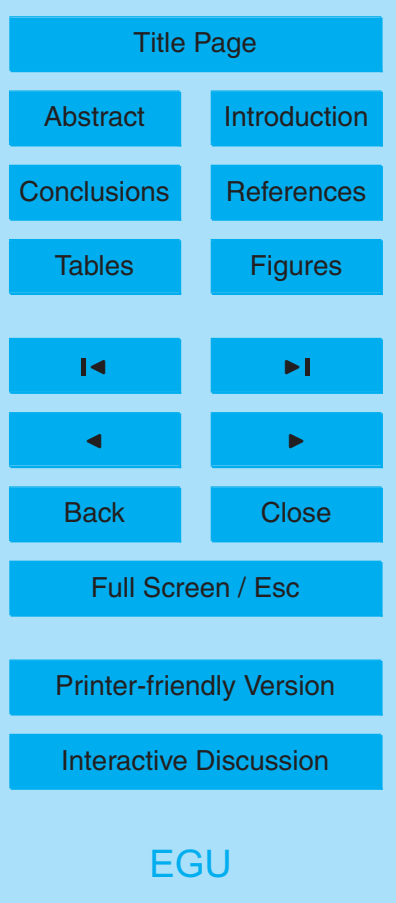


eter. Including CES has a notable impact on the Köhler curve, where now two local maxima (one at dry diameter, and one at $\sim 400 \mathrm{~nm}$ ). Unlike for leucine and pinic acid, introduction of CES increase does not impact the particle critical supersaturation.

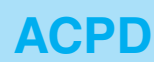

\subsection{Sensitivity of critical supersaturation to CES and interfacial energy}

5 As seen above, the effect of CES on Köhler curves may (but not always) have an impact on critical supersaturation. In fact, simulations suggest that the impact of interfacial energy on critical supersaturation exhibits a "threshold" type influence; this means that if $\gamma_{s l}$ is below a characteristic threshold, then the "dry" particle saturation ratio is the global maximum of the Köhler curve and determines the critical supersaturation (this

10 was seen in Fig. 6b). However, if $\gamma_{s l}$ exceeds a characteristic threshold, the solute remains in solution for small wet diameters, and the "second" Köhler curve maximum determines the critical supersaturation (as was seen in Figs. 6a and c). This threshold behavior is shown clearly in Fig. 7a, which presents critical supersaturation of pinonic acid particles as a function of dry diameter and $\gamma_{s /}$. For a given dry diameter, a jump 15 in critical supersaturation is seen when $\gamma_{s /}$ changes between 5 and $15 \mathrm{mN} \mathrm{m}^{-1}$; almost no difference is seen when $\gamma_{s /}$ varies from 0 to $5 \mathrm{mN} \mathrm{m}^{-1}$ and 15 to $60 \mathrm{mN} \mathrm{m}^{-1}$. Therefore, the importance of CES on particle critical supersaturation, can be assessed by comparing $\gamma_{s}$ with the threshold (if known). For leucine, (Fig. 7b) simulations suggest that the threshold $\gamma_{s /}$ is between 0 and $30 \mathrm{mN} \mathrm{m}^{-1}$; according to our measurements

20 (Table 3) $\gamma_{s l}>30 \mathrm{mN} \mathrm{m}^{-1}$ which mean that CES always reduces the critical supersaturation for this compound.

The simulations carried out in this study suggest that a typical "threshold" for $\gamma_{s l}$ ranges between 15 and $40 \mathrm{mN} \mathrm{m}^{-1}$. This range covers typical values of organic acid interfacial energy (Miller and Neogi, 1985), which according to the Söhnel (1982) cor25 relation (Fig. 5) corresponds to compounds with solubility $10^{-2} \mathrm{M}$ and above. Compounds with a lower solubility do not exhibit enough enhancement in solubility to have a profound impact on critical supersaturation (as was seen for pinonic acid, Fig. 6b).

\section{Cloud droplet activation: solubility revisited}

L. T. Padró and A. Nenes

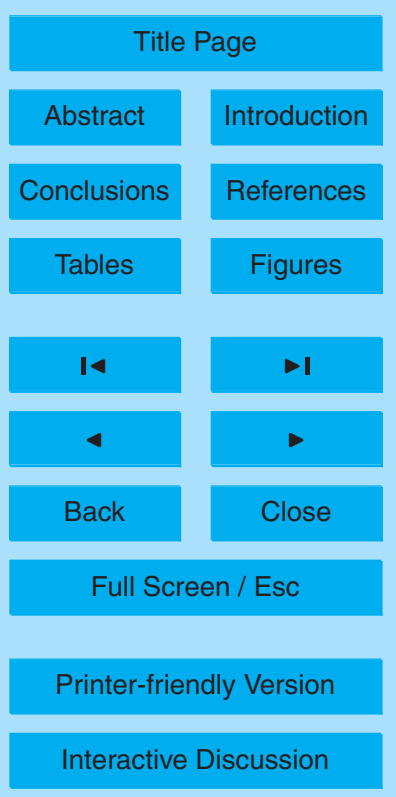




\subsection{Does CES improve predictions of CCN activity?}

The proxy we use for CCN activity is the minimum dry size of particles, $d_{50}$, that activate at a given level supersaturation of interest. We compare predictions of $d_{50}$ at 0.3-1.2\% supersaturation with our measurements and the data from Raymond and 5 Pandis (2002). Our observations of CCN activity were carried out by atomizing an aqueous solution of the compound of interest, drying the particles through a series of two diffusional dryers (residence time $\sim 5 \mathrm{~s}$ ) and then classified with a TSI 6080 electrostatic classifier. The classified aerosol was subsequently introduced into a DMT CCN counter (Roberts and Nenes, 2005; Lance et al., 2006) for measuring its CCN 10 activity. A detailed description of the procedure can be found in Lance et al. (2006). Predictions of $d_{50}$ are done by determining the dry size of particles with $s_{c}$ equal to $0.3,0.6 \%, 1.0 \%$, and $1.2 \%$. Predictions are carried out with (i.e., initially wet particles) and without CES (i.e., initially dry particles). For leucine, azelaic and phthalic acid, $\gamma_{s l}$ is determined from our measurements, while the Söhnel (1982) correlation is used for 15 the rest of the compounds.

The observed vs. predicted $d_{50}$ (without CES) are shown in Fig. 8a; with the exception of cases where $\Phi<1$ (Table 2 ), theory does not adequately predict $d_{50}$. The discrepancy in the predictions is from insufficient solute being dissolved in the CCN to explain its activity (i.e., $\Phi>1$ ). If CES is considered (Fig. 8b) all the solute is dissolved at the point of activation and the predictions are much closer to observations. This finding is consistent with the postulation that CES may be important for the activation of aerosol produced by drying of atomized aqueous solutions.

\section{Conclusions}

Laboratory and in-situ studies of aerosol-water interactions show that atmospheric hydrophobic particulate matter, if previously wet, may retain significant amounts of water even when exposed to very low relative humidity. We explore the possibility that parti-

\section{Cloud droplet} activation: solubility revisited

L. T. Padró and A. Nenes

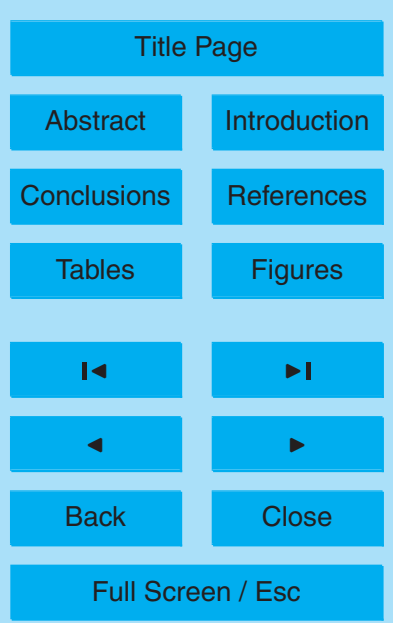

Printer-friendly Version

Interactive Discussion 
cle curvature, and its effect on solubility can explain this phenomenon. The augmented solubility, termed "Curvature Enhanced Solubility" (CES), is a strong function of interfacial energy, bulk solubility and nucleation embryo size. A stability analysis of the solute-solution system suggests that if the aerosol is initially wet and the nucleation 5 embryo size of solute is below a threshold, the formation of a solid phase is not favored, even if the solution is supersaturated, giving the "appearance" that the solute is completely soluble. Conversely, particles that are initially dry likely do not experience significant CES, and the amount of solute dissolved in the aqueous phase is consistent with its "bulk" solubility.

10 CES is introduced into Köhler theory to assess its impact on CCN activity for several organic compounds with a wide range of solubility in water. The interfacial energy between solute and aqueous phase required for quantification of CES is determined from $i$ ) concurrent measurements of contact angle and surface tension, and, ii) semiempirical correlations based on bulk solubility. We find that the impact of CES on CCN 15 activity (particle critical supersaturation) is not a smooth function of interfacial energy, but that the latter needs to exceed a characteristic threshold to see any impact. Subsequent increases of interfacial energy beyond the threshold would not further increase CCN activity. Measurements of CCN activity of the nine compounds studied here support the above; activation of atomized aerosol using two diffusional dryers (a relatively "soft" method of drying) is consistent with CES. On the contrary, it is known that if "aggressive" drying is used (i.e., heating), the aerosol completely dries and measured critical supersaturation are much higher (Broekhuizen et al., 2004), which is consistent with our expectation that CES is not important.

CES may often occur in ambient particles, since there is almost always water and 25 surfactants present in them. This implies that the concept of "partially soluble" atmospheric organics may not be relevant; even though each of the hundreds of compounds has its own bulk solubility, CES may force compounds above a "bulk" solubility threshold to always remain in the aqueous phase (i.e., be "completely soluble"), while those below the threshold to act as insoluble. If true, this could greatly simplify the repre-

\section{Cloud droplet activation: solubility revisited}

L. T. Padró and A. Nenes

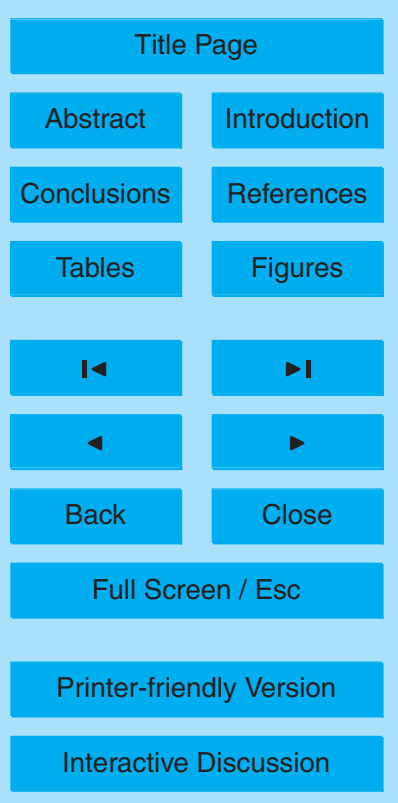

EGU 
sentation of organic impacts on CCN activity, as only a characterization of the surface tension depression and average molar mass of the soluble compounds with e.g., Köhler theory analysis (Padro et al., $2007^{1}$; Asa-Awuku et al., $2007^{2}$ ) is required.

Acknowledgements. This research was supported by a NSF CAREER Award, and a NASA 5 Earth System Science Fellowship.

\section{References}

Asa-Awuku, A. and Nenes, A.: The effect of solute dissolution kinetics on cloud droplet formation, J. Geoph. Res.-A., in press, 2007.

Bilde, M. and Svenningsson, B.: CCN activation of slightly soluble organics: the importance of small amounts of inorganic salt and particle phase, Tellus Series B-Chemical and Physical Meteorology, 56(2), 128-134, 2004.

Broekhuizen, K., Kumar, P. P., and Abbatt, J. P. D.: Partially soluble organics as cloud condensation nuclei: Role of trace soluble and surface active species, Geophys. Res. Lett., 31(1), L001107, doi:10.1029/2003GL018203, 2004.

15 Corrigan, C. E. and Novakov, T.: Cloud condensation nucleus activity of organic compounds: a laboratory study, Atmos. Environ., 33(17), 2661-2668, 1999.

Cruz, C. N. and Pandis, S. N.: A study of the ability of pure secondary organic aerosol to act as cloud condensation nuclei, Atmos. Environ., 31(15), 2205-2214, 1997.

Hartz, K. E. H., Tischuk, J. E., Chan, M. N., Chan, C. K., Donahue, N. M., and Pandis, S. N.: Cloud condensation nuclei activation of limited solubility organic aerosol, Atmos. Environ., 40(4), 605-617, 2006.

Henning, S., Rosernorn, T., D'Anna, B., Gola, A. A., Svenningsson, B., and Bilde, M.: Cloud droplet activation and surface tension of mixtures of slightly soluble organics and inorganic salt, Atmos. Chem. Phys., 5, 575-582, 2005,

25 http://www.atmos-chem-phys.net/5/575/2005/.

\footnotetext{
${ }^{2}$ Asa-Awuku,A., Nenes, A., Sullivan, A. P., Hennigan, C., and Weber, R. J.: Investigation of molar volume and surfactant characteristics of water-soluble organic compounds in biomass burning aerosol, in review, 2007.
}

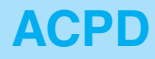

$7,2325-2355,2007$

\section{Cloud droplet activation: solubility revisited}

L. T. Padró and A. Nenes

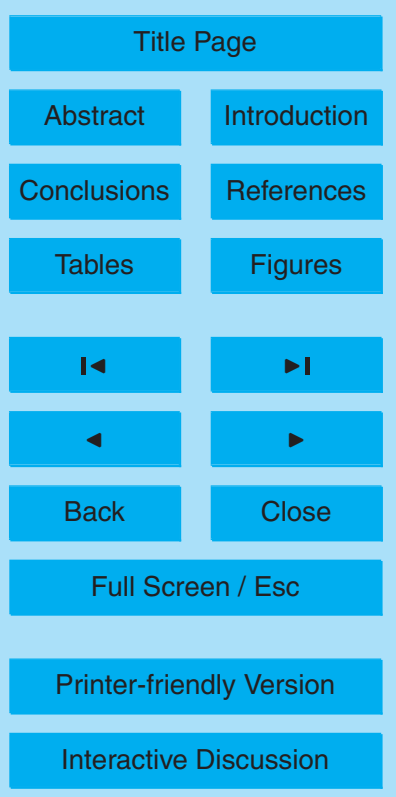

EGU 
Holmberg, K., Jönsson, B., Kronberg, B., and Lindman, B.: Surfactants and Polymers in Aqueous Solution, John Wiley \& Sons, Ltd., 2003

Hori, M., Ohta, S., Murao, N., and Yamagata, S.: Activation capability of water soluble organic substances as CCN, J. Aerosol Sci., 34(4), 419-448, 2003.

5 Kohler, $\mathrm{H} .:$ The nucleus in and the growth of hygroscopic droplets, Transactions of the Faraday Society, 32(2), 1152-1161, 1936.

Kumar, P. P., Broekhuizen, K., and Abbatt, J. P. D.: Organic acids as cloud condensation nuclei: Laboratory studies of highly soluble and insoluble species, Atmos. Chem. Phys., 3, 509$520,2003$.

10 Lance, S., Medina, J., Smith, J. N., and Nenes, A.: Mapping the operation of the DMT continuous flow CCN counter, Aerosol Sci. Technol., 40, 242-254, 2006.

Marcolli, C., Luo, B. P., and Peter, T.: Mixing of the organic aerosol fractions: liquids as the thermodynamically stable phases, J. Phys. Chem. A, 180(12), 2216-2224, 2004.

Miller, C. A. and Neogi, P.: Interfacial Phenomena: Equilibrium and Dynamic Effects, MARCEL 15 DEKKER, INC. New York, 1985.

Nenes, A., Charlson, R. J., Facchini, M. C., Kulmala, M., Laaksonen, A., and Seinfeld, J. H.: Can chemical effects on cloud droplet number rival the first indirect effect?, Geophys. Res. Lett., 29(17), 1848, doi:10.1029/2002GL015295, 2002.

Nielsen, A. E.: Kinetics of Precipitation, Macmillan. New York, 1964.

20 Novakov, T. and Penner, J. E.: Large Contribution of Organic Aerosols to Cloud-CondensationNuclei Concentrations, Nature, 365(6449), 823-826, 1993.

Prenni, A. J., DeMott, P. J., Kreidenweis, S. M., Sherman, D. E., Russell, L. M., and Ming, Y.: The effects of low molecular weight dicarboxylic acids on cloud formation, J. Phys. Chem. A, 105(50), 11240-11248, 2001.

Raymond, T. M. and Pandis, S. N.: Cloud activation of single-component organic aerosol particles, J. Geophys. Res.-A., 107(D24), 4787, doi:10.1029/2002JD002159, 2002.

Roberts, G. C. and Nenes, A.: A continuous-flow streamwise thermal-gradient CCN chamber for atmospheric measurements, Aerosol Sci. Technol., 39(3), 206-211, 2005.

Seinfeld, J. H. and Pandis, S.: Atmospheric Chemistry and Physics, John Wiley, New York, 1997.

Shulman, M. L., Jacobson, M. C., Carlson, R. J., Synovec, R. E., and Young, T. E.: Dissolution behavior and surface tension effects of organic compounds in nucleating cloud droplets, Geophys. Res. Lett., 23(3), 277-280, 1996.

\section{Cloud droplet activation: solubility revisited}

L. T. Padró and A. Nenes

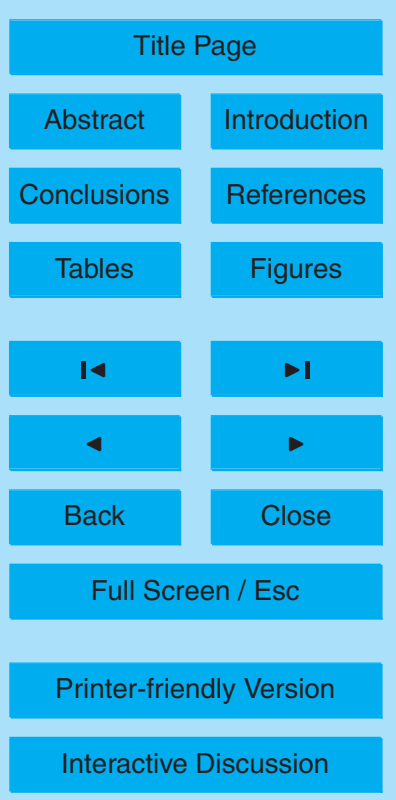

EGU 
Sohnel, O.: Electrolyte Crystal Aqueous-Solution Interfacial-Tensions from Crystallization Data, Journal of Crystal Growth, 57(1), 101-108, 1982.

Spelt, J. K. and Li, D.: Applied Surface Thermodynamics, MARCEL DEKKER, INC. New York, 1996.

5 Wexler, A. S. and Seinfeld, J. H.: 2nd-Generation Inorganic Aerosol Model, Atmospheric Environment Part a-General Topics, 25(12), 2731-2748, 1991.

Wu, W. J. and Nancollas, G. H.: The dissolution and growth of sparingly soluble inorganic salts: A kinetics and surface energy approach, Pure and Applied Chemistry, 70(10), 1867-1872, 1998.

10 Wu, W. J. and Nancollas, G. H.: Determination of interfacial tension from crystallization and dissolution data: a comparison with other methods, Advances in Colloid and Interface Science, 79(2-3), 229-279, 1999.

\section{ACPD}

7, 2325-2355, 2007

\section{Cloud droplet} activation: solubility revisited

L. T. Padró and A. Nenes

Title Page

Abstract

Introduction

Conclusions

References

Tables

Figures

14

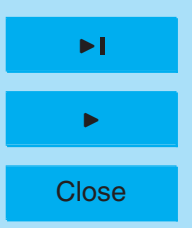

Back 


\section{ACPD}

Table 1. Compounds considered in this study.

\begin{tabular}{llll}
\hline Compound & $\rho_{s}\left(\mathrm{~kg} \mathrm{~m}^{-3}\right)$ & $M_{s}\left(\mathrm{~kg} \mathrm{~mole}^{-1}\right)$ & $C_{\text {bulk }}\left(\mathrm{kg} \mathrm{kg}^{-1}\right)$ \\
\hline Pinonic Acid & $786^{\mathrm{a}}$ & $0.184^{\mathrm{b}}$ & $6.75 \times 10^{-3 \mathrm{~b}}$ \\
Glutamic Acid & $1538^{\mathrm{a}}$ & $0.147^{\mathrm{b}}$ & $6.95 \times 10^{-3 \mathrm{~b}}$ \\
Adipic Acid & $1360^{\mathrm{a}}$ & $0.146^{\mathrm{b}}$ & $1.825 \times 10^{-2 \mathrm{~b}}$ \\
Norpinic Acid & $800^{\mathrm{a}}$ & $0.172^{\mathrm{b}}$ & $4.7 \times 10^{-2 \mathrm{~b}}$ \\
Pinic Acid & $800^{\mathrm{a}}$ & $0.186^{\mathrm{b}}$ & $8.46 \times 10^{-2 \mathrm{~b}}$ \\
Glutaric Acid & $1424^{\mathrm{a}}$ & $0.132^{\mathrm{b}}$ & $1.235^{\mathrm{b}}$ \\
Azelaic Acid & $1225^{\mathrm{c}}$ & $0.188^{\mathrm{c}}$ & $2.447 \times 10^{-3 c}$ \\
Phthalic Acid & $2180^{\mathrm{c}}$ & $0.166^{\mathrm{c}}$ & $1.415 \times 10^{-3 c}$ \\
Leucine & $1293^{\mathrm{c}}$ & $0.131^{\mathrm{c}}$ & $2.3 \times 10^{-2 \mathrm{c}}$ \\
\hline
\end{tabular}

Cloud droplet activation: solubility revisited

L. T. Padró and A. Nenes

Title Page

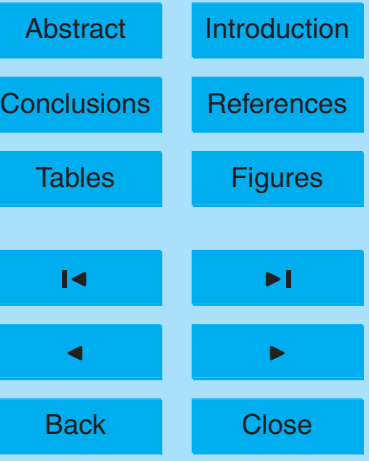

${ }^{a}$ CRC Handbook (2002).

${ }^{\mathrm{b}}$ Raymond and Pandis (2002).

${ }^{c}$ Yaws (1999).

\section{Full Screen / Esc}




\section{ACPD}

$7,2325-2355,2007$

Table 2. Value of $\Phi$ (ratio solute moles required for activation over those allowed by bulk solubility) at various supersaturations. Bold numbers denote cases where bulk solubility alone is insufficient for activating CCN.

\begin{tabular}{lllll}
\hline Compound & SS $=0.3 \%^{\mathrm{a}}$ & $\mathrm{SS}=0.6 \%^{\mathrm{b}}$ & $\mathrm{SS}=1 \%^{\mathrm{a}}$ & $\mathrm{SS}=1.2 \%^{\mathrm{b}}$ \\
\hline Adipic Acid & 0.666 & $\mathrm{~N} / \mathrm{A}$ & $\mathbf{2 . 2 1 3}$ & $\mathrm{N} / \mathrm{A}$ \\
Glutaric Acid & 0.009 & $\mathrm{~N} / \mathrm{A}$ & 0.030 & $\mathrm{~N} / \mathrm{A}$ \\
Glutamic Acid & $\mathbf{1 . 7 6 2}$ & $\mathrm{N} / \mathrm{A}$ & $\mathbf{5 . 8 5 1}$ & $\mathrm{N} / \mathrm{A}$ \\
Norpinic Acid & 0.305 & $\mathrm{~N} / \mathrm{A}$ & $\mathbf{1 . 0 1 3}$ & $\mathrm{N} / \mathrm{A}$ \\
Pinic Acid & 0.183 & $\mathrm{~N} / \mathrm{A}$ & 0.608 & $\mathrm{~N} / \mathrm{A}$ \\
Pinonic Acid & $\mathbf{2 . 2 7 1}$ & $\mathrm{N} / \mathrm{A}$ & $\mathbf{7 . 5 4 4}$ & $\mathrm{N} / \mathrm{A}$ \\
Azelaic Acid & N/A & $\mathbf{1 2 . 7 8 1}$ & $\mathrm{N} / \mathrm{A}$ & $\mathbf{2 5 . 4 8 7}$ \\
Phthalic Acid & N/A & 19.509 & N/A & 38.903 \\
Leucine & 0.119 & 0.948 & 4.361 & $\mathbf{1 . 8 9 0}$ \\
\hline
\end{tabular}

a Critical supersaturations from Raymond and Pandis (2002).

${ }^{\mathrm{b}}$ Critical supersaturations measured during this study.

\section{Cloud droplet activation: solubility revisited}

L. T. Padró and A. Nenes

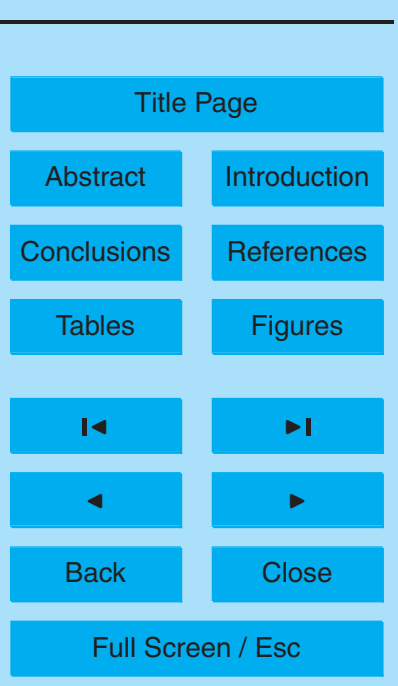

Printer-friendly Version

Interactive Discussion 


\section{ACPD}

$7,2325-2355,2007$

\section{Cloud droplet activation: solubility revisited}

Table 3. Surface tension, contact angle and interfacial energy for organic/organic solid-liquid interphase at $25^{\circ} \mathrm{C}$. Uncertainty in measured quantities corresponds to one standard deviation.

\begin{tabular}{llll}
\hline Substrate/Drop System & $\sigma\left(\mathrm{mN} \mathrm{m}^{-1}\right)$ & $\theta\left(^{\circ}\right)$ & $\gamma_{s /}\left(\mathrm{mN} \mathrm{m}^{-1}\right)$ \\
\hline Azelaic/ Azelaic Solution & 69.5 & $26.39 \pm 7.48$ & $0.79 \pm 0.10$ \\
Azelaic/Water & 71.15 & $21.96 \pm 8.11$ & $0.57 \pm 0.71$ \\
Phthalic/ Phthalic Solution & 71.77 & $22.83 \pm 16.11$ & $0.65 \pm 0.66$ \\
Phthalic/Water & 71.76 & $12.13 \pm 0.62$ & $0.51 \pm 0.62$ \\
Leucine/Leucine Solution & 71.29 & $97.09 \pm 8.26$ & $32.07 \pm 2.80$ \\
Leucine/ Water & 71.87 & $57.43 \pm 4.25$ & $9.84 \pm 3.52$ \\
\hline
\end{tabular}

Title Page

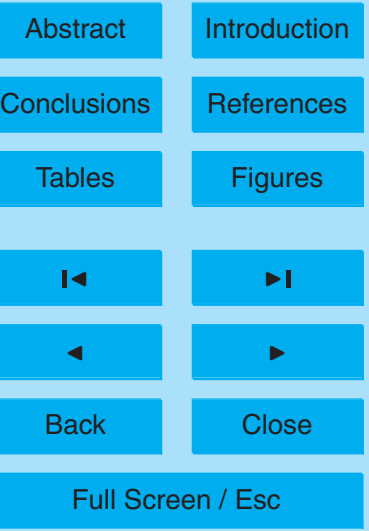

Printer-friendly Version

Interactive Discussion 


\section{ACPD}

7, 2325-2355, 2007

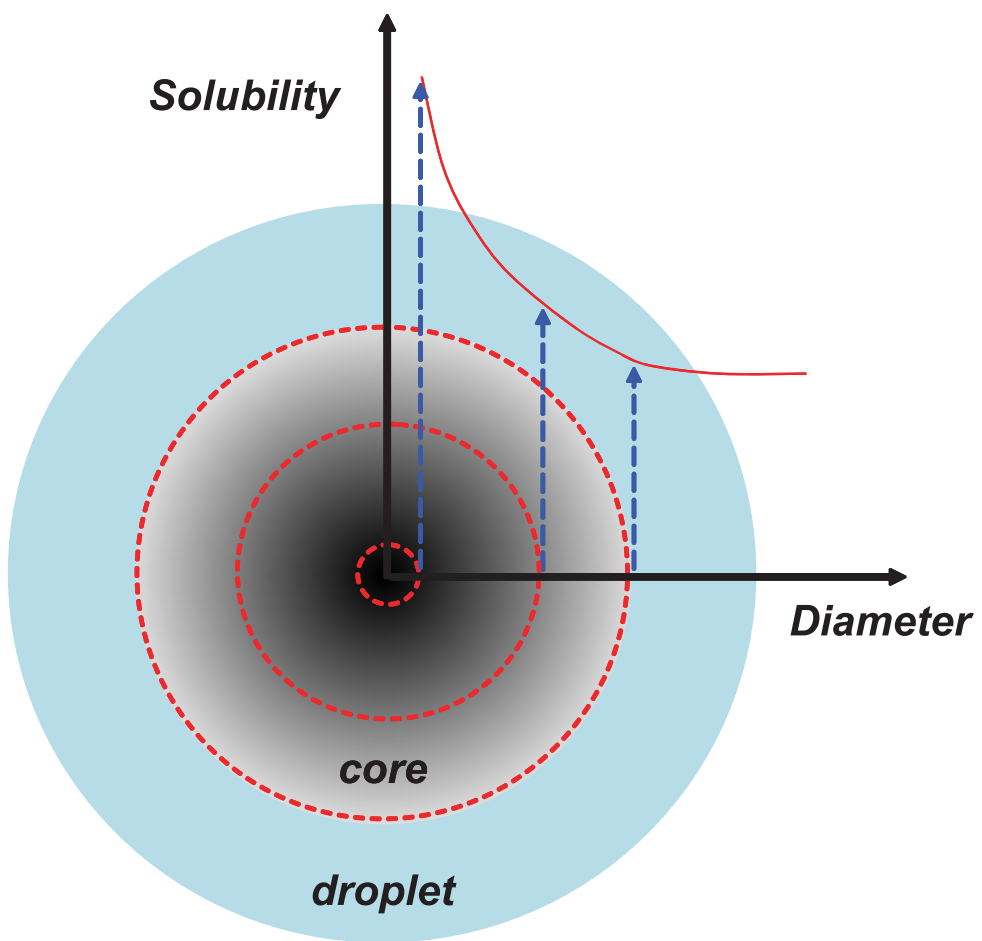

Cloud droplet activation: solubility revisited

L. T. Padró and A. Nenes

Title Page

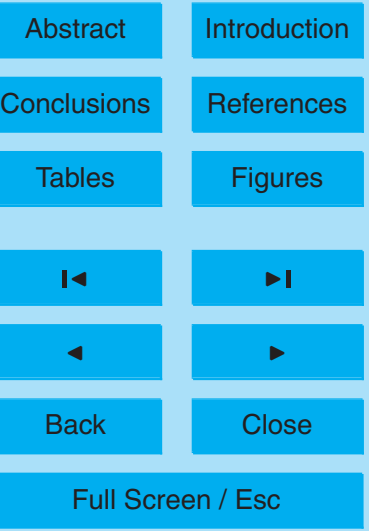

Fig. 1. Illustration of the importance of solute curvature on solubility. 


\section{ACPD}

7, 2325-2355, 2007

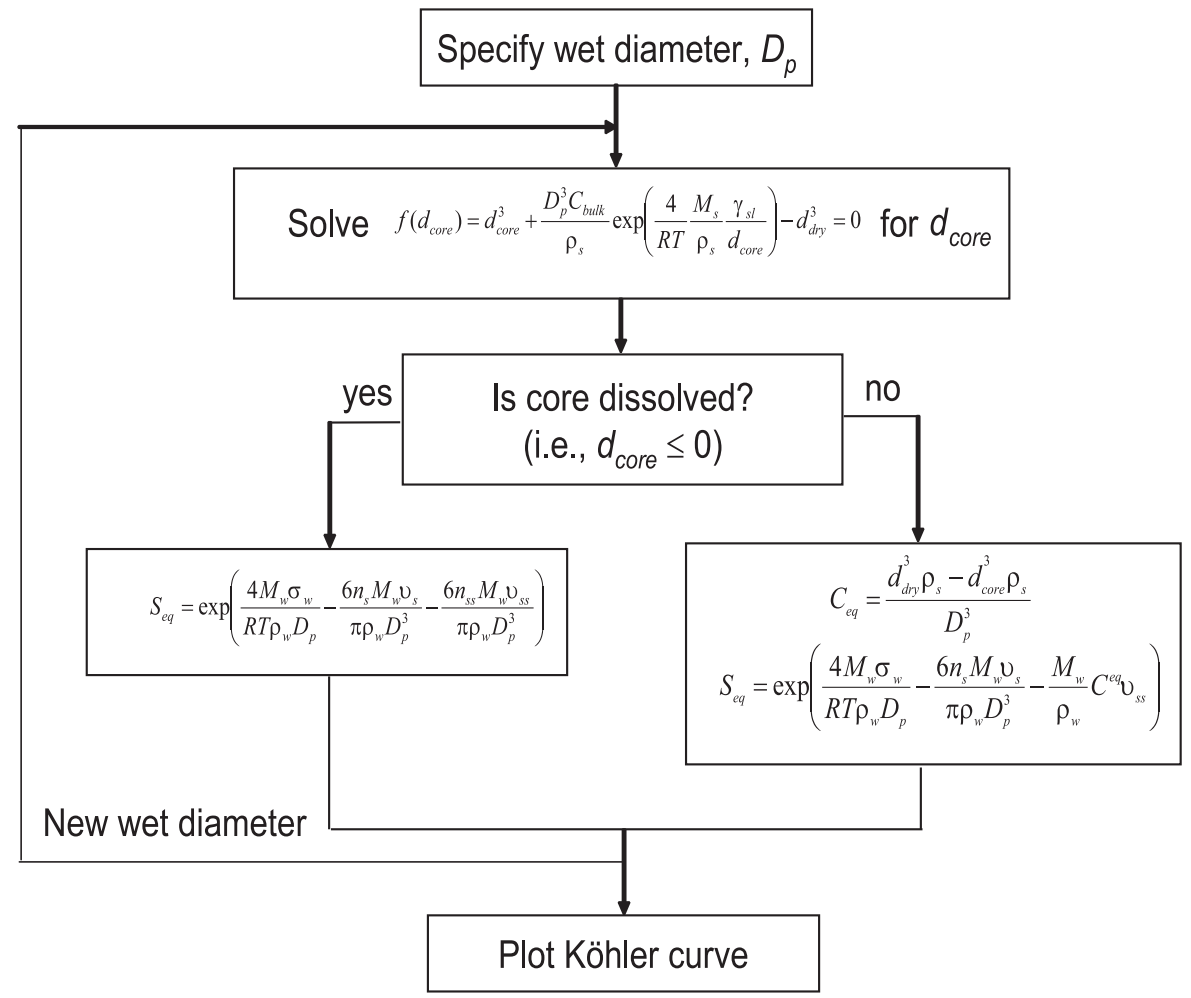

Cloud droplet activation: solubility revisited

L. T. Padró and A. Nenes

Title Page

Abstract

Introduction

Conclusions

References

Tables

Figures

14

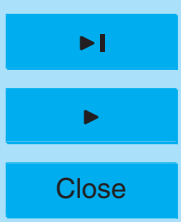

Back

Close

Full Screen / Esc

Printer-friendly Version

Fig. 2. Algorithm used for introducing CES into Köhler theory.

Interactive Discussion 


\section{ACPD}

7, 2325-2355, 2007

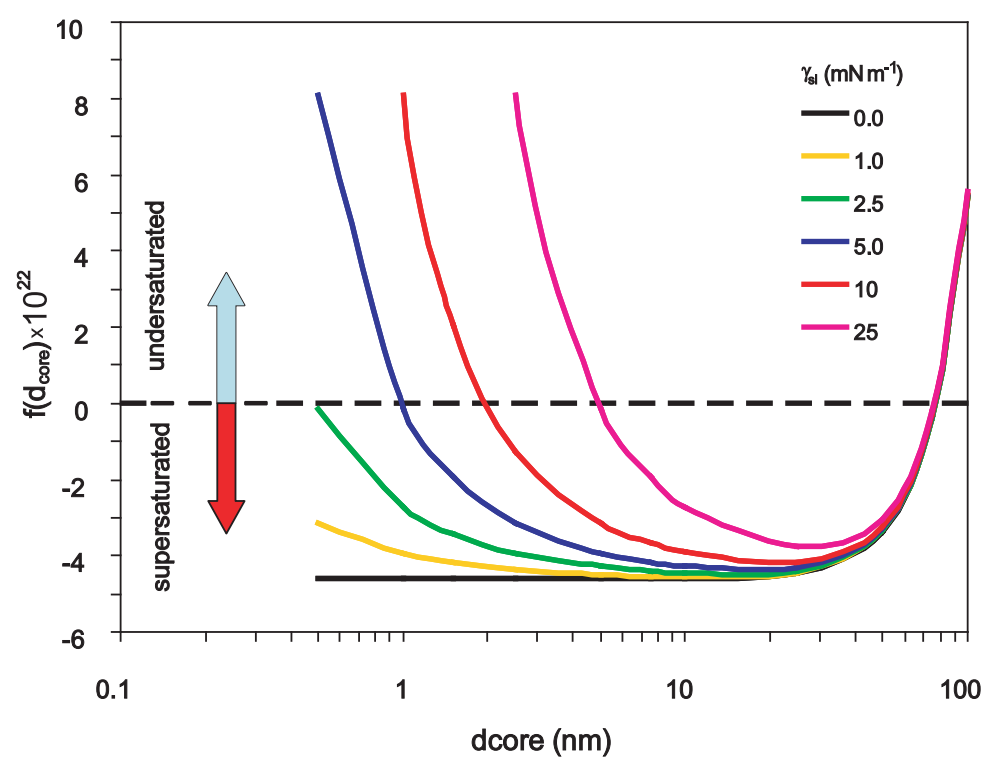

\section{Cloud droplet activation: solubility revisited}

L. T. Padró and A. Nenes

Title Page

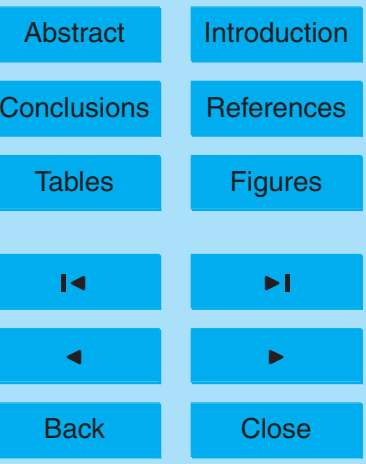

Fig. 3. Regions of thermodynamic stability for the solute-water system Eq. (10) for different interfacial energy. The curves correspond to a wet CCN with $D_{p}=0.5 \mu \mathrm{m}, \rho_{s}=1760 \mathrm{~kg} \mathrm{~m}^{-3}$, $M_{s}=0.132 \mathrm{~kg} \mathrm{~mol}^{-1}, C_{\text {bulk }}=1 \mathrm{~g} \mathrm{~kg}^{-1}, d_{\text {dry }}=100 \mathrm{~nm}, \mathrm{~T}=298 \mathrm{~K}$.

\section{Full Screen / Esc}

Printer-friendly Version

Interactive Discussion 


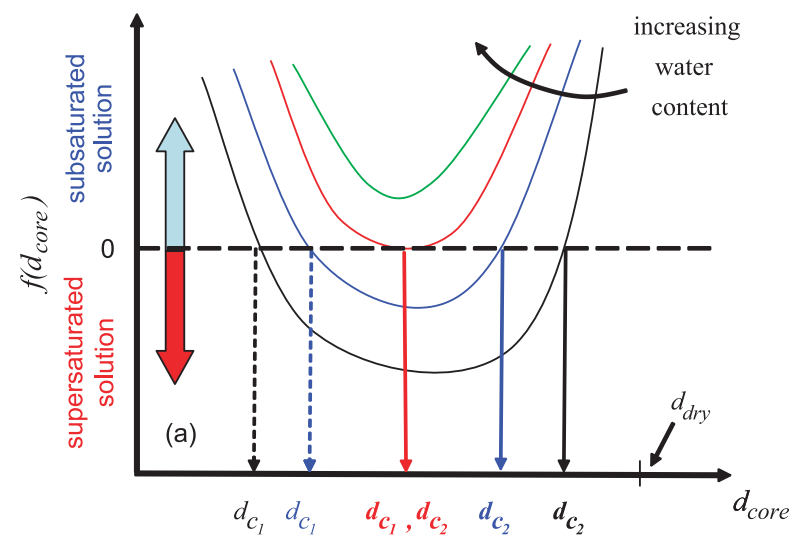

\section{ACPD}

$7,2325-2355,2007$

\section{Cloud droplet activation: solubility revisited}

L. T. Padró and A. Nenes

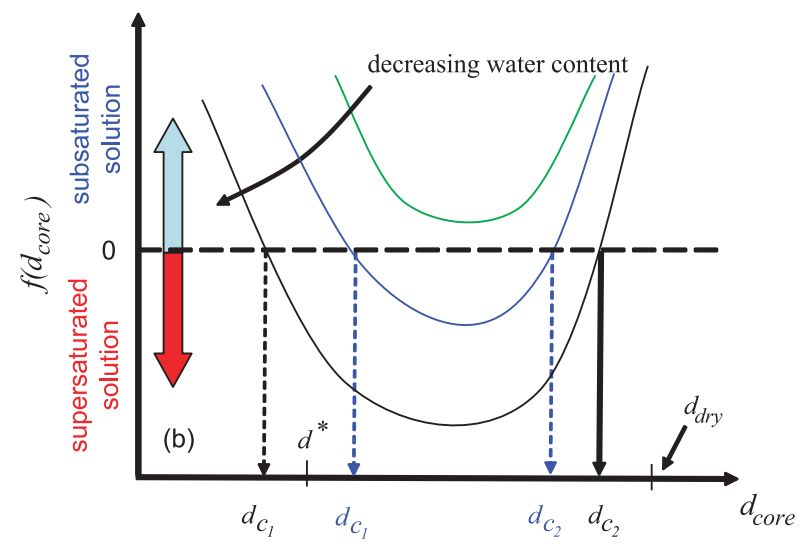

Title Page

Abstract

Conclusions

Tables

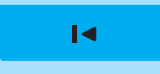

4

Back
Introduction

References

Figures

I

$>$

Close

\section{Full Screen / Esc}

Printer-friendly Version

Fig. 4. Regions of thermodynamic stability for the solute-water system when (a) water condenses upon an initially dry particle, and, (b) water evaporates from a particle that is initially wet.

Interactive Discussion 


\section{ACPD}

$7,2325-2355,2007$

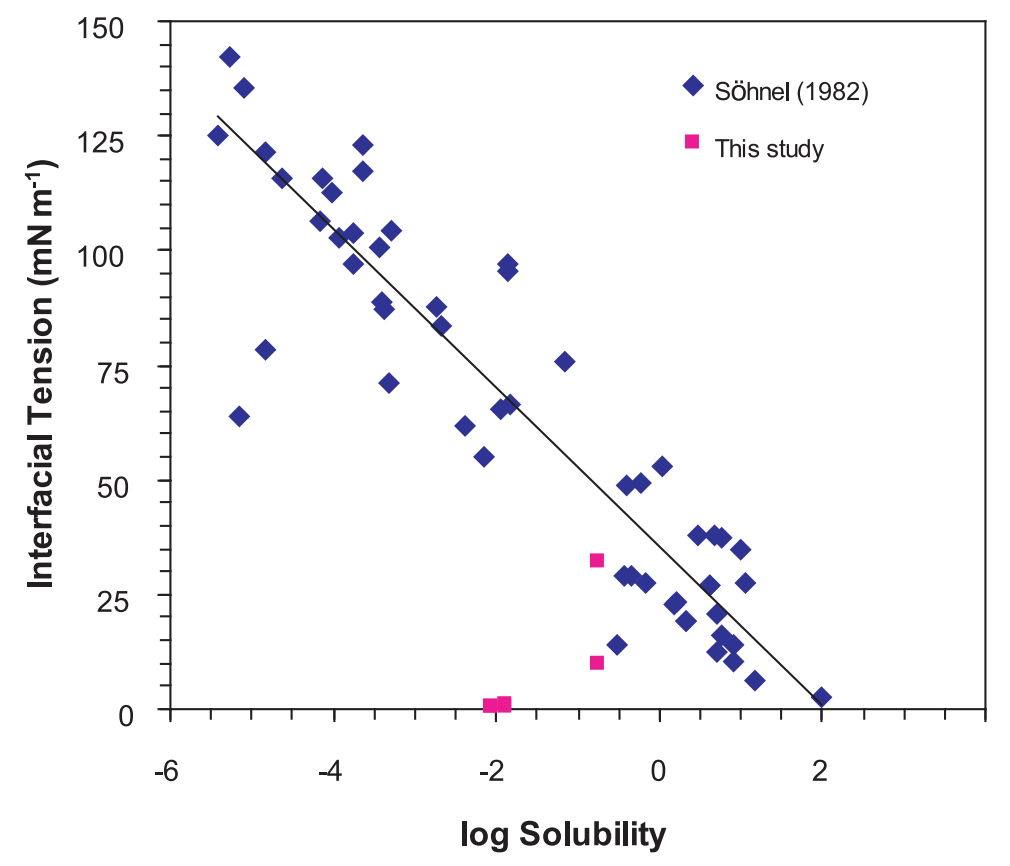

\section{Cloud droplet activation: solubility revisited}

L. T. Padró and A. Nenes

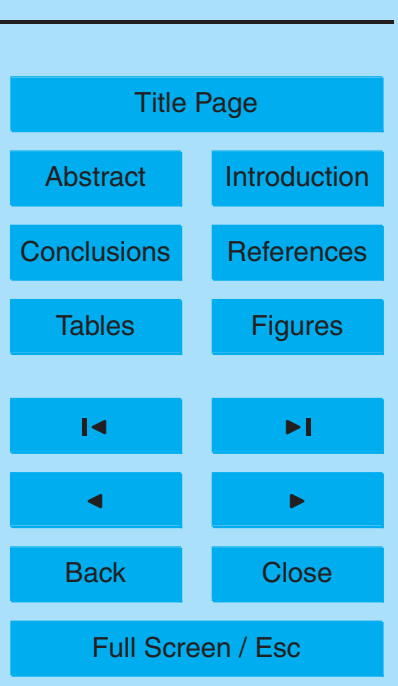

Fig. 5. Interfacial tension as a function of substance solubility as predicted by the Söhnel correlation (Sohnel, 1982). Blue diamonds correspond to sparingly soluble and soluble substances studied in Söhnel (1982) and pink squares correspond to compounds considered in this study.

Printer-friendly Version

Interactive Discussion 

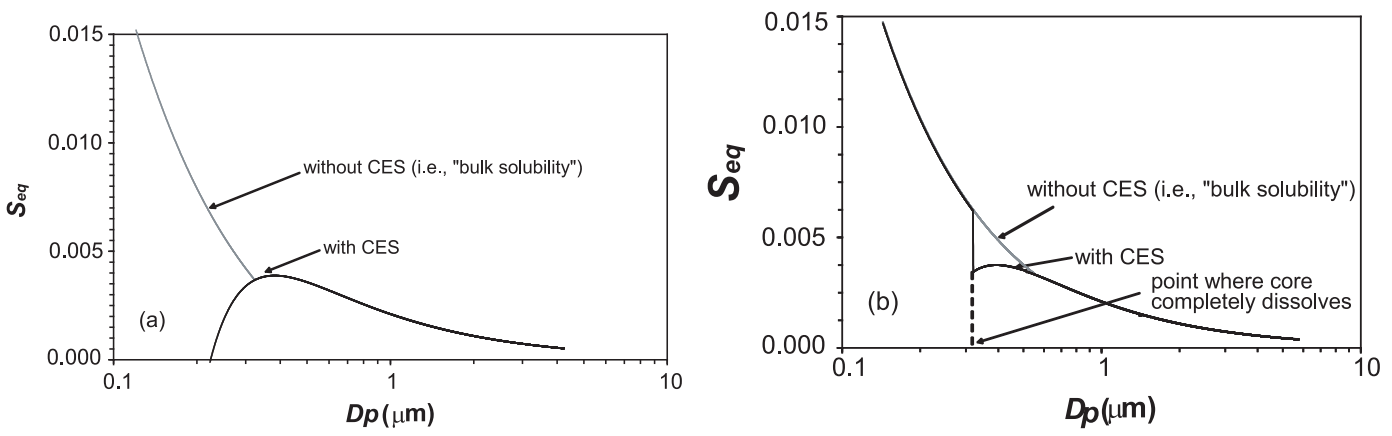

\section{ACPD}

$7,2325-2355,2007$

\section{Cloud droplet activation: solubility revisited}

L. T. Padró and A. Nenes

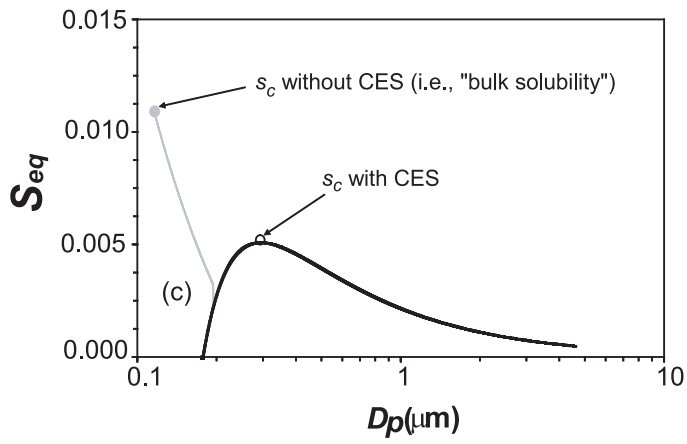

Title Page

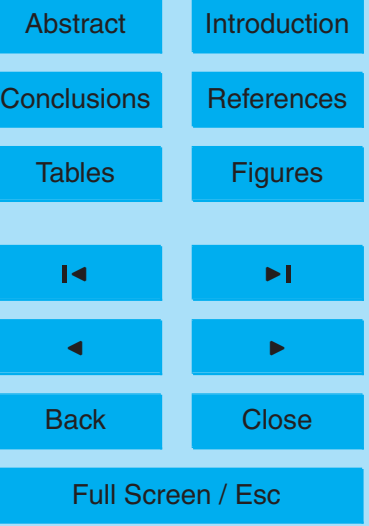

Fig. 6. (a) Comparison of Köhler curves for a $84 \mathrm{~nm}$ dry diameter leucine without curvature enhanced solubility (grey line) and with curvature enhanced solubility (black line), (b) Same as $6 a$, but for a pinonic acid particle of $114 \mathrm{~nm}$ dry diameter, (c) Same as $6 a$, but for a pinic acid particle of $92 \mathrm{~nm}$ dry diameter. Predictions used our measured interfacial energy (Table 3) for leucine and $\gamma_{s /}=30 \mathrm{mN} \mathrm{m}^{-1}$ for pinonic and pinic acid. 


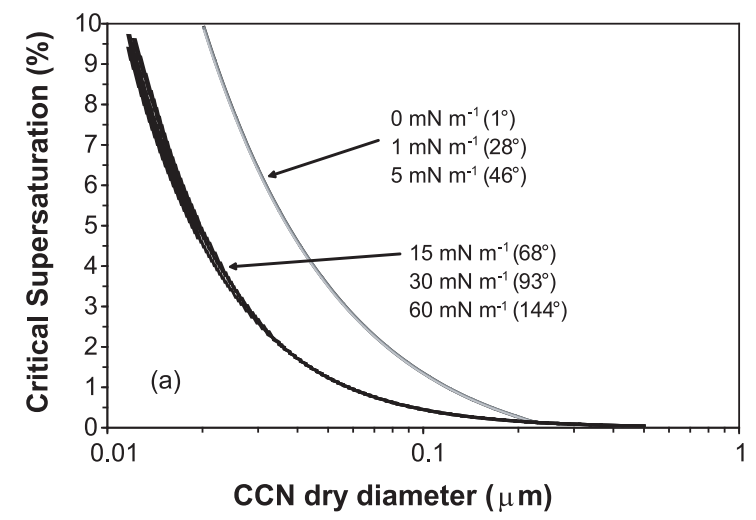

\section{ACPD}

$7,2325-2355,2007$

\section{Cloud droplet activation: solubility revisited}

L. T. Padró and A. Nenes

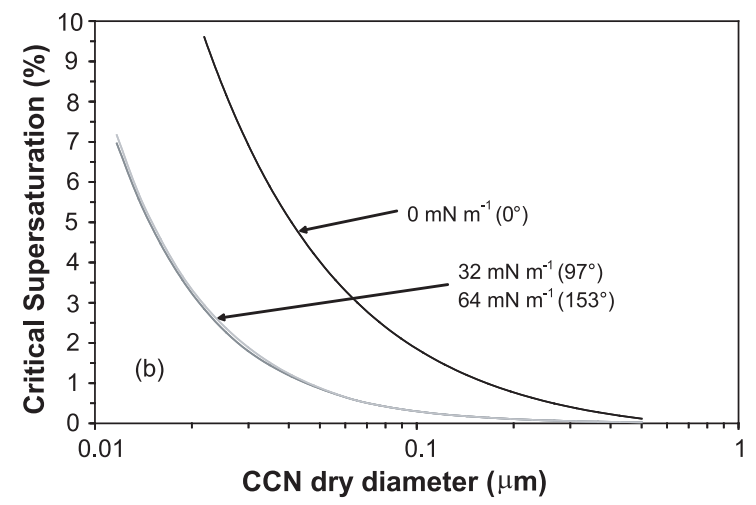

Title Page

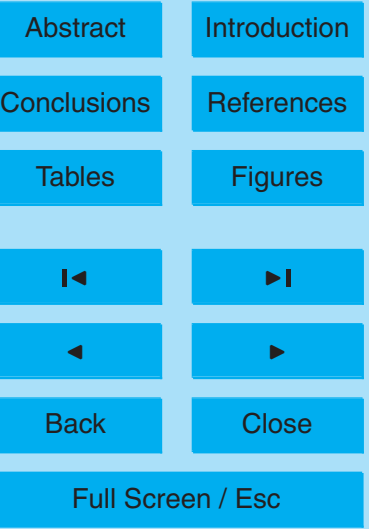

Fig. 7. (a) Interfacial energy contribution to CES of pinic acid for zero interfacial energy Printer-friendly Version (black line), $1 \mathrm{mN} \mathrm{m}^{-1}$ (dark grey line), $5 \mathrm{mN} \mathrm{m}^{-1}$ (light grey line), $15 \mathrm{mN} \mathrm{m}^{-1}$ (dotted black line), $30 \mathrm{mN} \mathrm{m}^{-1}$ (dotted dark grey line), and $60 \mathrm{mN} \mathrm{m}^{-1}$ (dotted light grey line). Number in parenthesis is the corresponding contact angle when assuming surface tension of water. (b) Interfacial energy contribution to CES of leucine for zero interfacial energy (black line), $32 \mathrm{mN} \mathrm{m}^{-1}$ and $64 \mathrm{mN} \mathrm{m}^{-1}$ interfacial energy (grey line). 


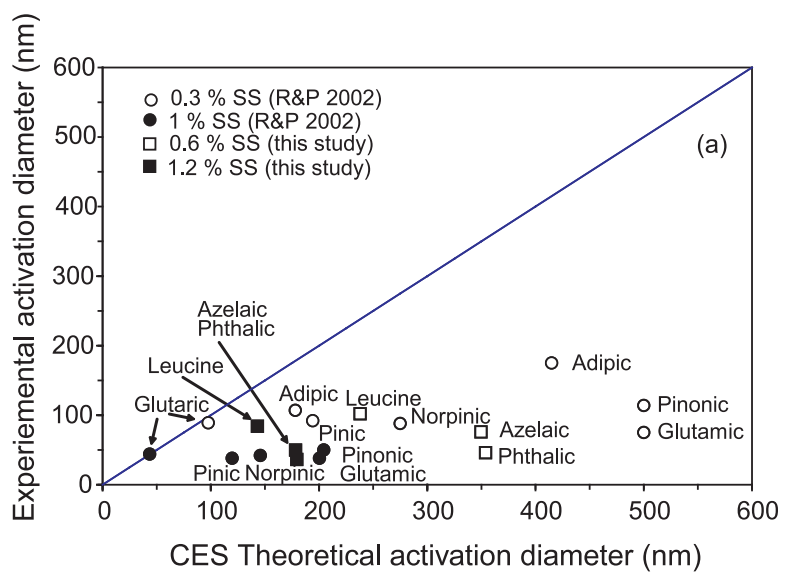

\section{ACPD}

$7,2325-2355,2007$

\section{Cloud droplet activation: solubility revisited}

L. T. Padró and A. Nenes

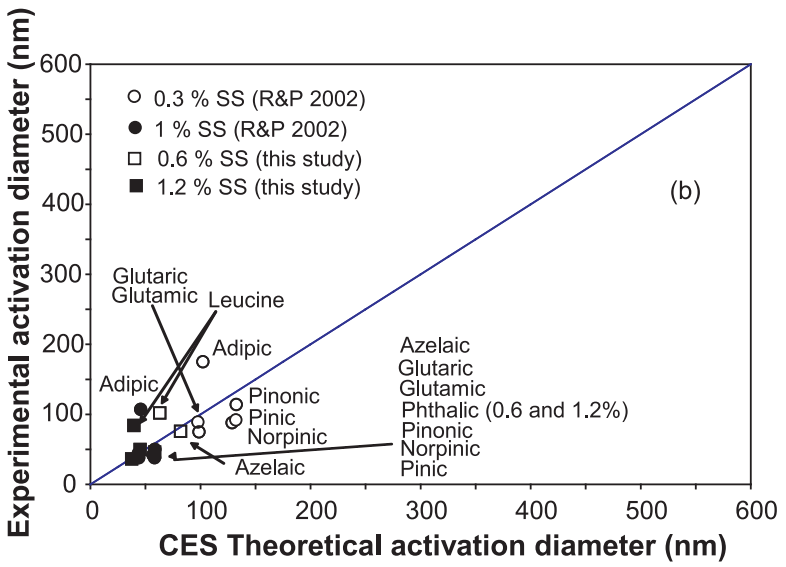

Title Page

Abstract

Conclusions

Tables

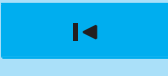

4

\section{Back}

Full Screen / Esc

Printer-friendly Version

Interactive Discussion
Fig. 8. Measured vs. predicted $d_{50}$ for all species and supersaturations (a) without CES and (b) with CES. Predictions used our measured interfacial energy (Table 3) for azelaic acid, phthalic acid, and leucine; $\gamma_{s l}=30 \mathrm{mN} \mathrm{m}^{-1}$ was used for the remaining compounds. 